\title{
Clinical outcomes following surgical mitral valve repair or replacement in patients with rheumatic heart disease: a meta-analysis
}

\author{
Yefan Jiang", Chen Wang", Geng Li, Si Chen \\ Department of Cardiovascular Surgery, Union Hospital, Tongji Medical College, Huazhong University of Science and Technology, Wuhan, China \\ Contributions: (I) Conception and design: Y Jiang, S Chen; (II) Administrative support: None; (III) Provision of study materials or patients: None; (IV) \\ Collection and assembly of data: Y Jiang, C Wang; (V) Data analysis and interpretation: Y Jiang, C Wang, G Li; (VI) Manuscript writing: All authors; \\ (VII) Final approval of manuscript: All authors. \\ "These authors contributed equally to this work. \\ Correspondence to: Si Chen, MD, PhD; Geng Li, MD. Department of Cardiovascular Surgery, Union Hospital, Tongji Medical College, Huazhong \\ University of Science and Technology, Jiefang Road, No. 1277, Wuhan 430022, China. Email: Chensi0220@hotmail.com; ligeng@hust.edu.cn.
}

Background: The clinical outcome of mitral valve repair (MVP) is considerably more favorable than that of mitral valve replacement (MVR) in patients with degenerative mitral disease. However, rheumatic heart disease (RHD) is still the predominant cause of mitral valve surgery in developing countries and the advantages of MVP in RHD have still not been definitely proven. The aim of this meta-analysis was thus to evaluate the suitability of MVP in patients with RHD. Considering the difference between mechanical and biological valves, we distinguished them from each other and compared them with MVP individually.

Methods: A comparison of clinical outcomes of MVP and MVR in patients with RHD was performed based on clinical trial data. Relevant articles published from January 1, 1990 until March 1, 2020 were identified in Pubmed, Cochrane Library, and China National Knowledge Infrastructure database (CNKI). Studies that lacked direct comparisons between MVP and MVR were excluded.

Results: A total of 16 studies with 8659 patients were included in the analysis. The MVP group displayed lower early and long-term mortality, and fewer valve-related events and major adverse events. However, this patient group required more reoperations compared with the MVR group. Similar results were observed after distinguishing between mechanical and bioprosthetic valves to compare MVP with MVR (mech-valves), but no statistically significant difference was identified in the reoperation rate between MVP and MVR (bio-valves). MVP was further associated with increased risk of mitral reoperation in patients undergoing concomitant aortic valve replacement (AVR) surgery but without any improved early and long-term survival. Conclusions: MVP and MVR are beneficial for patients with RHD. For skilled surgeons, MVP can be performed for some suitable patients with RHD and is preferred for elderly patients or patients with contraindications of anticoagulation. However, MVR is more appropriate when concomitant AVR is needed.

Keywords: Rheumatic heart disease (RHD); mitral valve repair (MVP); mitral valve replacement (MVR); clinical outcomes; meta-analysis

Submitted Apr 27, 2020. Accepted for publication Nov 15, 2020.

doi: $10.21037 / \mathrm{atm}-20-3542$

View this article at: http://dx.doi.org/10.21037/atm-20-3542

(c) Annals of Translational Medicine. All rights reserved. 


\section{Introduction}

Rheumatic heart disease (RHD) is one of the major causes of mitral valve diseases in developing countries (1). RHD can result in mitral stenosis, mitral regurgitation, and mixed lesions which leads to abnormal hemodynamics and eventually heart failure, thereby requiring surgical intervention. Mitral valve repair (MVP) has a lower rate of reoperation, thromboembolism, and valve infection compared to mitral valve replacement (MVR) $(2,3)$, and has been the preferred choice for patients with degenerative, myxomatous, or ischemic mitral valve disease $(4,5)$. However, its association with significant fibrosis, scarring, sub-valvular pathology, and rheumatic pathology progressing (6-8) into RHD disease has led to questions surrounding its benefit over the past decades. Therefore, a meta-analysis was performed to evaluate whether MVP exhibits improved clinical outcomes compared to MVR in patients with RHD. Subgroups of mechanical and bioprosthetic valves were also analyzed for more detailed comparison.

We present the following article in accordance with the PRISMA reporting checklist (available at http://dx.doi. org/10.21037/atm-20-3542).

\section{Methods}

\section{Search strategy}

PubMed, Cochrane Library, and CNKI were searched to identify research published from January 1, 1990 until March 2, 2020, that compared the clinical outcomes of MVP versus MVR in patients with RHD. The following key terms were used either alone or in combination: "mitral valve repair", "mitral valvuloplasty", "mitral reconstruction", "mitral valve annuloplasty", "MVP", "mitral valve replacement", "MVR", "rheumatic", and "RHD". The reference list of relevant articles and reviews were manually scrutinized to find additional studies.

\section{Eligibility criteria}

The inclusion criteria were as follows: (I) direct comparison of MVP versus MVR; (II) clinical outcomes information (early survival, long-term survival, freedom from reoperation, freedom from valve-related events, freedom from major adverse events) reported with sufficient detail to facilitate the extraction of hazard or odd ratios, and their standard errors or Kaplan-Meier curves. When several studies were reported from the same institution with sample overlap, only the most recent study was included. Two authors (Dr. Yefan Jiang and Dr. Chen Wang) independently extracted data from studies which met the inclusion criteria. Any disagreements were resolved by consensus or a discussion with a professional and independent co-worker (Dr. Si Chen). Studies that met the inclusion criteria were rated according to the NewcastleOttawa Scale (NOS), using three main criteria: study group selection, comparability between groups, and ascertainment of outcomes (9). Data quality was independently assessed by two authors (Yefan Jiang and Chen Wang). A study with a NOS score of 6 or higher was deemed as high quality.

\section{Statistical analysis}

Summary hazard ratios (HR) for long-term survival, freedom from reoperation, freedom from valve-related events, and odds ratios (OR) for early mortality and freedom from major adverse events were obtained as weighted averages of the measures from the individual studies, with inverse variances used as weights. The methods of Parmar et al. (10), Williamson et al. (11), and Tierney et al. (12) were used to calculate the estimated HR and its variance. A Q-statistic and $\mathrm{I}^{2}$ (index of inconsistency) test was used to quantify the degree of heterogeneity in all studies. A random effects model was used in case of significant heterogeneity $\left(\mathrm{P}<0.1\right.$ or $\left.\mathrm{I}^{2}>50 \%\right)$. Sensitivity analyses were performed by omitting each study in sequence. Publication bias was assessed by visual inspection of funnel plots. Data were analyzed with RevMan 5.3 (The Nordic Cochrane Center, The Cochrane Collaboration, Copenhagen, Denmark).

\section{Results}

\section{Study search}

The study selection process is summarized in Figure 1. Based on the literature search, 16 studies $(1,8,13-26)$ satisfied the inclusion criteria, all of which were retrospective. The trials included a total of 8,659 patients, of whom 2,467 underwent MVP and 6,192 underwent MVR from 1976 to 2017. The characteristics of individual studies are summarized in Table 1. The prevalence of risk factors of interest is displayed in Table 2, and the main clinical outcomes are shown in Table 3. Quality assessment showed a NOS score of 6 or higher for all studies with a mean NOS score of 7 , indicating the 


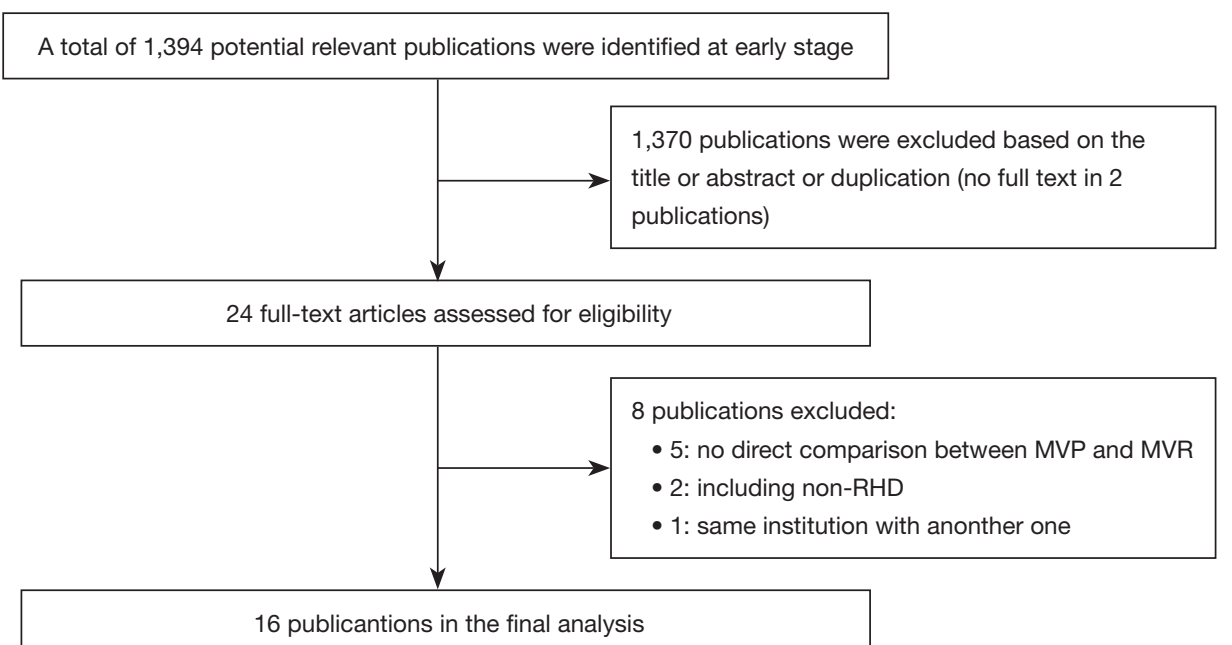

Figure 1 The flowchart outlining the literature search process.

Table 1 The characteristics of the individual studies

\begin{tabular}{|c|c|c|c|c|c|c|c|c|c|c|c|c|c|c|}
\hline \multirow{2}{*}{ Study } & \multirow{2}{*}{ Country } & \multirow{2}{*}{ Study period- } & \multicolumn{3}{|c|}{ Surgery } & \multicolumn{2}{|c|}{$\begin{array}{c}\text { Mean age } \\
\text { (years) }\end{array}$} & \multicolumn{2}{|c|}{ Male/female } & \multicolumn{4}{|c|}{ Concomitant operations } & \multirow{2}{*}{ Way of MVP } \\
\hline & & & MVP & MVR(Mech) & MVR(Bio) & MVP & MVR & MVP & MVR & & MVP & $\begin{array}{c}\text { MVR } \\
\text { (Mech) }\end{array}$ & $\begin{array}{l}\text { MVR } \\
\text { (Bio) }\end{array}$ & \\
\hline Kim 2010, (13) & South Korea & 1997-2007 & 122 & 418 & 0 & 41.7 & 51 & $27 / 95$ & $157 / 261$ & MAZE & 79 & 116 & & $\begin{array}{c}\mathrm{R}, \mathrm{C}, \mathrm{CF}, \mathrm{LE}, \\
\mathrm{RSA}\end{array}$ \\
\hline \multirow{2}{*}{$\begin{array}{l}\text { Wang 2008, } \\
\text { (14) }\end{array}$} & Taiwan China & 1997-2005 & 33 & 41 & 18 & 49.7 & 58.1 & $12 / 21$ & $20 / 39$ & TVP & 15 & \multicolumn{2}{|l|}{36} & $\mathrm{R}, \mathrm{C}, \mathrm{CF}, \mathrm{D}, \mathrm{LE}$ \\
\hline & & & & & & & & & & MAZE & 13 & \multicolumn{2}{|l|}{5} & \multirow{6}{*}{$\begin{array}{l}\mathrm{R}, \mathrm{C}, \mathrm{CF}, \mathrm{CR}, \\
\mathrm{LE}, \mathrm{PMS}, \mathrm{SA}\end{array}$} \\
\hline \multirow[t]{5}{*}{ Kim 2018, (8) } & South Korea & 1997-2005 & 294 & 1,134 & 303 & 43.9 & 54.04 & $70 / 224$ & $471 / 966$ & TVP & 99 & 467 & 155 & \\
\hline & & & & & & & & & & AVR & 51 & 410 & 84 & \\
\hline & & & & & & & & & & CABG & 6 & 38 & 22 & \\
\hline & & & & & & & & & & MAZE & 116 & 465 & 149 & \\
\hline & & & & & & & & & & Aortic & 29 & 22 & 4 & \\
\hline \multirow{3}{*}{$\begin{array}{l}\text { Cotrufo 1996, } \\
\text { (15) }\end{array}$} & Italy & 1981-1996 & 300 & 240 & 0 & 43 & 50 & $34 / 266$ & $66 / 174$ & LAT & 11 & 19 & & $\mathrm{C}$ \\
\hline & & & & & & & & & & LAL & 31 & 3 & & \\
\hline & & & & & & & & & & $L A T+L A L$ & 6 & 10 & & \\
\hline \multirow{2}{*}{$\begin{array}{l}\text { Geldenhuys } \\
2011,(1)\end{array}$} & South Africa & 2000-2010 & 69 & 63 & 6 & 36.9 & 40.9 & $15 / 54$ & $11 / 58$ & TVP & 4 & 2 & & \multirow{2}{*}{$\begin{array}{c}\text { R, C, CF, CR, } \\
\text { RSA, ETT, LCC, } \\
\text { LE, LR }\end{array}$} \\
\hline & & & & & & & & & & MAZE & 9 & 4 & & \\
\hline \multirow{3}{*}{$\begin{array}{l}\text { Duran 1991, } \\
\text { (16) }\end{array}$} & Saudi Arabia & 1988-1990 & 136 & 31 & 36 & 26.5 & 33.97 & $65 / 71$ & $32 / 35$ & $\mathrm{AV}$ & 15 & 44 & & \multirow{3}{*}{$\begin{array}{c}\mathrm{R}, \mathrm{C}, \mathrm{Ch}, \mathrm{L}, \\
\mathrm{RSA}\end{array}$} \\
\hline & & & & & & & & & & $\mathrm{TV}$ & 17 & 10 & & \\
\hline & & & & & & & & & & $A V+T V$ & 11 & 17 & & \\
\hline $\begin{array}{l}\text { Russell 2017, } \\
\text { (17) }\end{array}$ & Australia & 2001-2013 & 119 & \multicolumn{2}{|c|}{1,078} & 57.3 & 62 & $50 / 69$ & $309 / 769$ & CABG & 24 & 201 & & - \\
\hline
\end{tabular}

Table 1 (continued) 
Table 1 (continued)

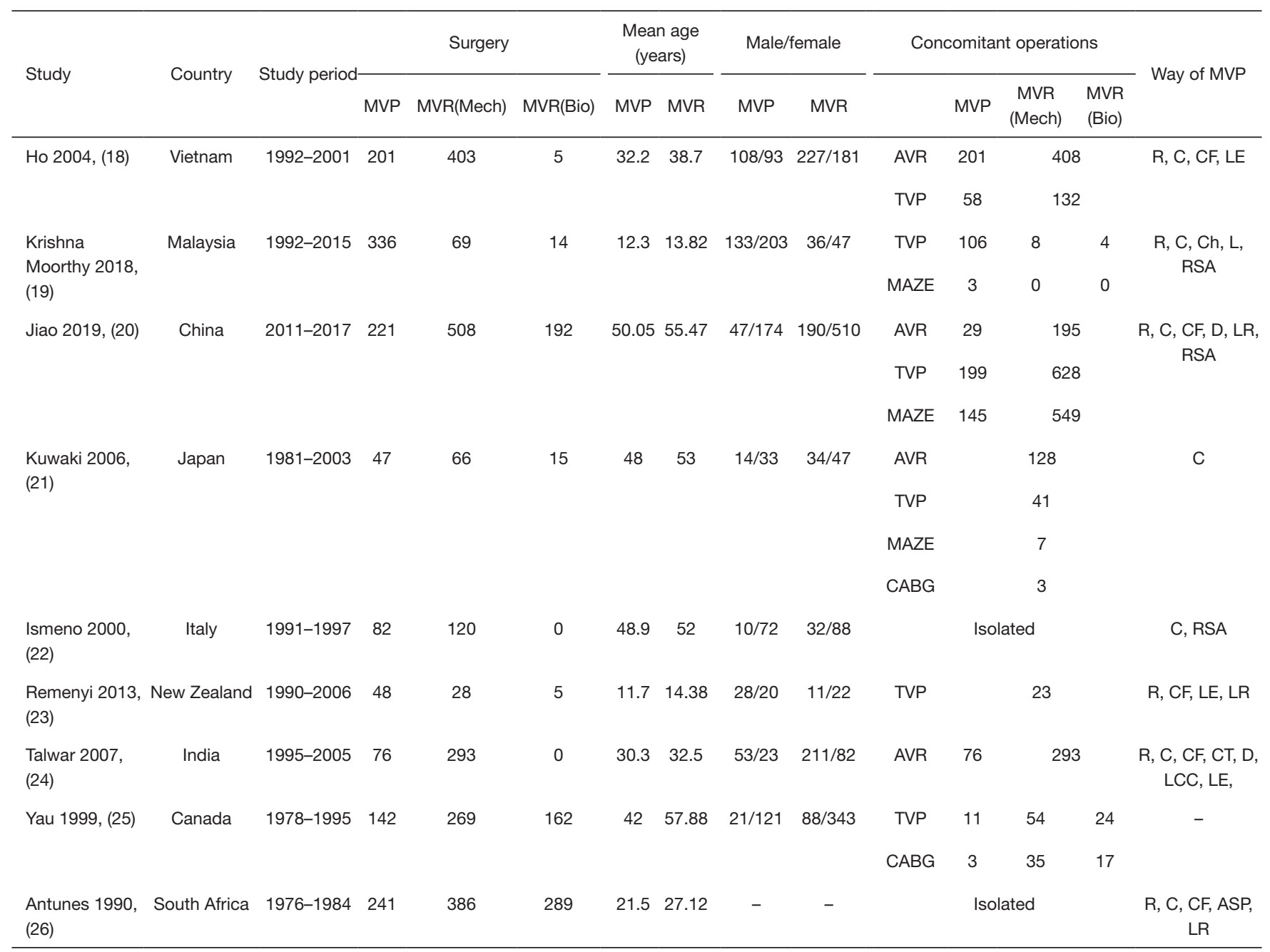

MVP, mitral valve repair; MVR, mitral valve replacement; Mech, mechanical valves; Bio, bioprosthetic valves; MAZE, Maze procedure; TV, tricuspid procedure; TVP, tricuspid valvuloplasty; AV, aortic valve procedure; AVR, aortic valve replacement; CABG, coronary artery bypass graft; LAT, left atrial thrombectomy; LAL, left appendage ligature; ASP, annulus suture plication; C, commissurotomy; CF, chordae formation; CR, chordae replacement; CT, cuspal thinning; Ch, chordae procedure; D, decalcification; ETT, edge to edge suture; LCC, leaflet cleft closures; LE, leaflet extension; LR, leflet resection; L, leaflet procedure; R, ring; RSA, release of subvalvular apparatus; SA, strip annuloplasty.

presence of high methodological quality.

\section{Early mortality}

All 16 studies provided information on early mortality, as defined by death occurring within 30 days after surgery or in-hospital at any time (21); 10 studies $(8,13,15,19,20,22-26)$ reported patients with mechanical valves, and 6 studies $(8,19,20,23,25,26)$ reported information on patients with bioprosthetic valves. The advantages of repair over replacement were strongly evident, irrespective of whether the artificial valves were mechanical or bioprosthetic. (MVP vs. MVR: OR: $0.58,95 \%$ CI: 0.42-0.82, Figure $2 A$; MVP vs. MVR (mech-valves): OR: 0.48, 95\% CI: $0.32-0.73$, Figure 2B; MVP vs. MVR (bio-valves): OR: 0.36, 95\% CI: 0.20-0.63, Figure 2C).

\section{Long-term survival}

Data for long-term survival were obtained from 14 studies $(1,8,13-14,18-27)$. Two studies $(13,21)$ were excluded as they reported cardiac death instead of all-cause mortality. The heterogeneity among those studies was relatively high $\left(\mathrm{I}^{2}=56 \%, \mathrm{P}=0.01\right)$, and a random effects model was applied. 


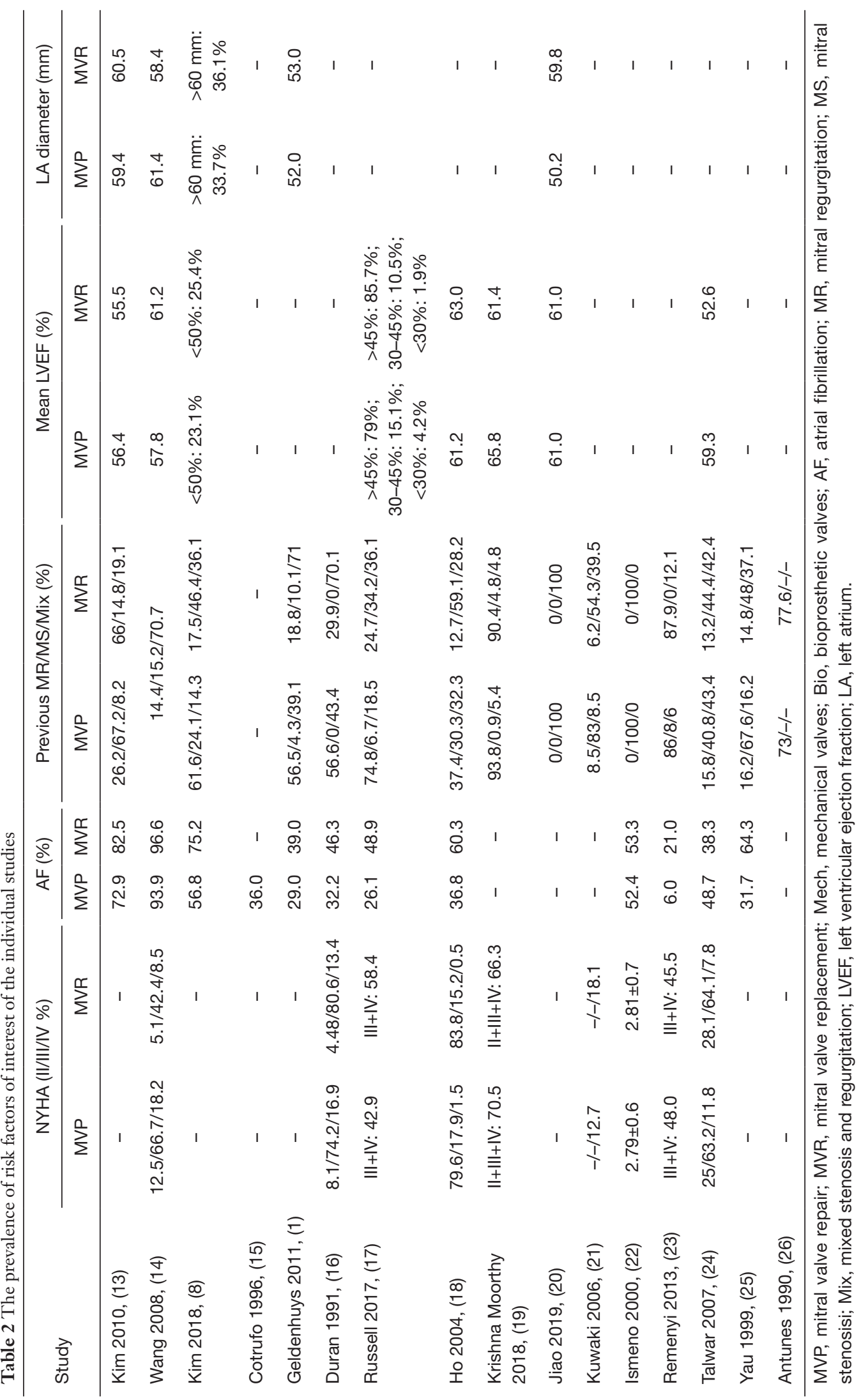




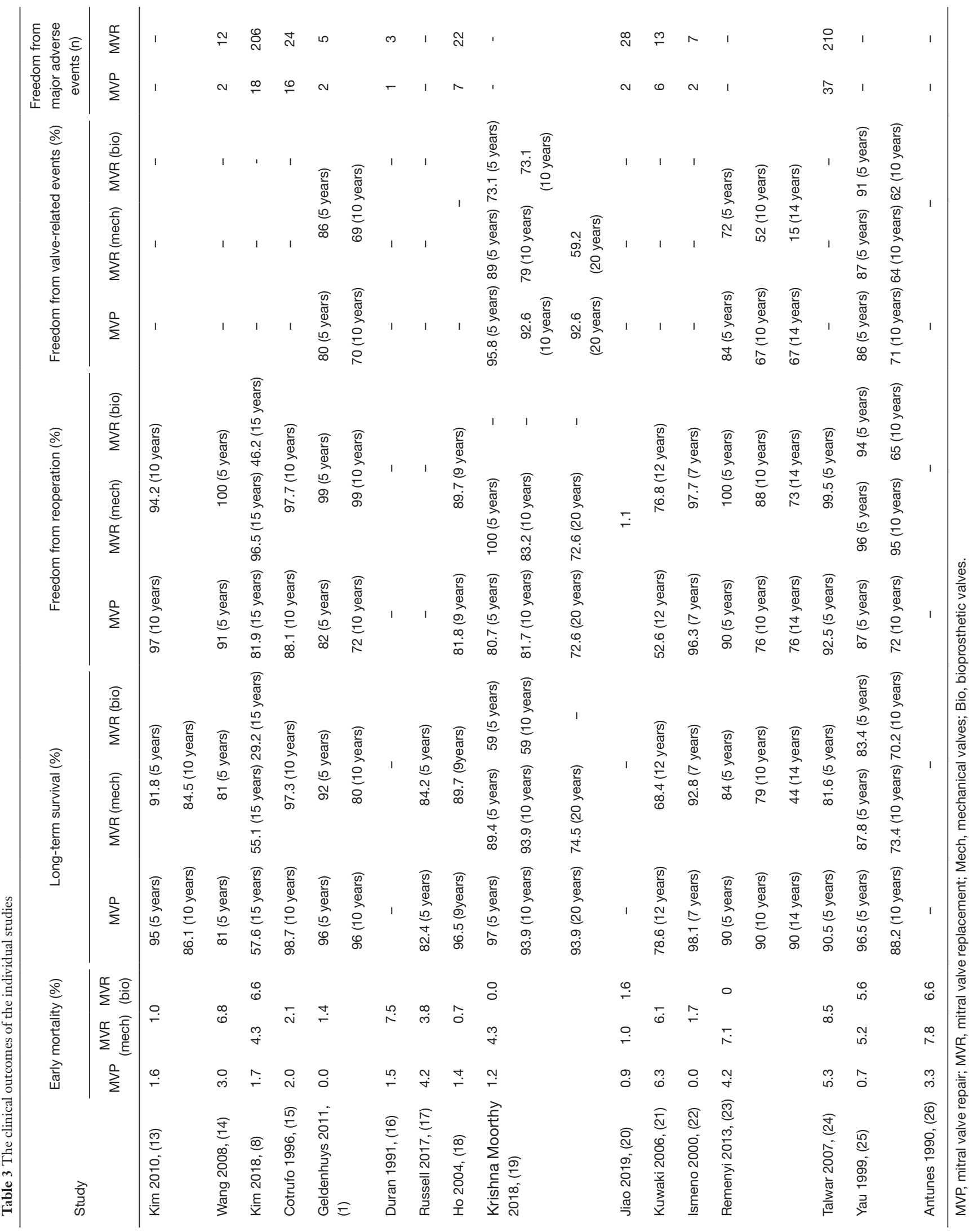




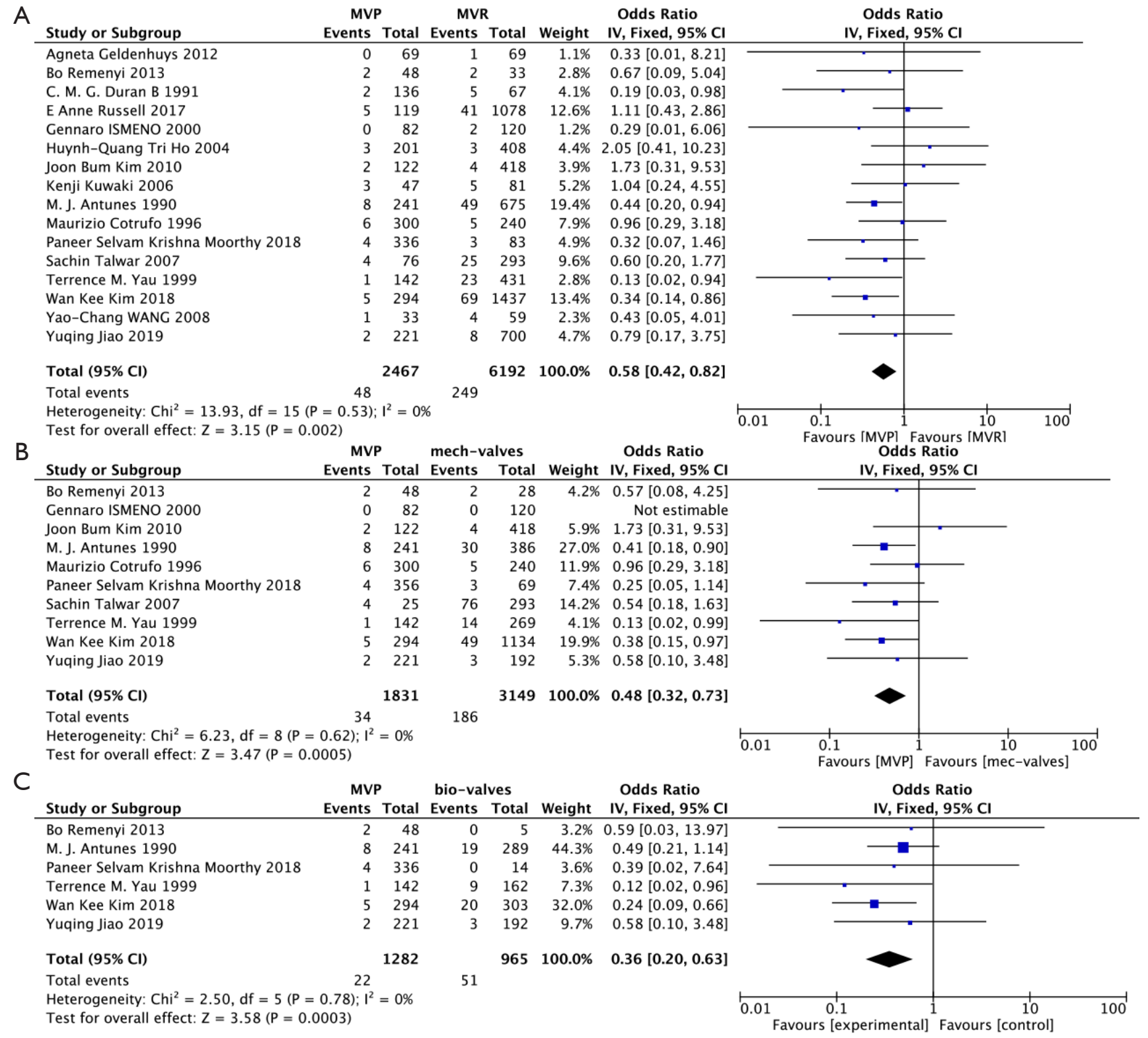

Figure 2 Meta-analysis for early mortality. (A) MVP vs. MVR; (B) MVP vs. MVR (mech-valves); (C) MVP vs. MVR (bio-valves). MVP, mitral valve repair; MVR, mitral valve replacement.

Eight studies $(8,13,19,22-26)$ documented details of patients with mechanical valves while four studies $(8,19,25,26)$ reported information on patients with bioprosthetic valves. However, significant heterogeneity was observed among studies related to bioprosthetic valves $\left(I^{2}=83 \%, P=0.0006\right)$, which was subsequently deemed acceptable after the removal of data reported by Krishna Moorthy et al. (19), which did not influence the overall results. The results indicated that patients in the MVR group exhibited an increased long-term risk of death (MVP vs. MVR: HR: 0.49, 95\% CI: $0.34-0.70$, Figure $3 A$; MVP vs. MVR (mech-valves): HR: $0.51,95 \%$ CI: $0.40-0.64$, Figure 3B; MVP vs. MVR (bio-valves): HR: 0.31, 95\% CI: 0.24-0.40, Figure 3C).

\section{Freedom from reoperation}

Analysis of freedom from reoperation was based on data obtained from nine studies $(1,8,14,15,19,21,22,24,25)$, 


\begin{tabular}{|c|c|c|c|c|c|c|c|c|c|c|}
\hline $\mathrm{A}_{\text {Study or Subgroup }}$ & $\log [$ & Hazar & d Ratio] & SE & Weight & $\begin{array}{c}\text { Hazard Ratio } \\
\text { IV, Random, } 95 \% \mathrm{CI}\end{array}$ & & $\begin{array}{r}\text { Hazarc } \\
\text { IV, Rando }\end{array}$ & $\begin{array}{l}\text { rd Ratio } \\
\text { om, } 95 \% \mathrm{Cl}\end{array}$ & \\
\hline Agneta Geldenhuys 20 & & & -0.18 & 0.59 & $6.2 \%$ & $0.84[0.26,2.65]$ & & & & \\
\hline Bo Remenyi 2013 & & & -0.99 & 0.57 & $6.4 \%$ & $0.37[0.12,1.14]$ & & & & \\
\hline E Anne Russell 2017 & & & -0.15 & 0.39 & $9.7 \%$ & $0.86[0.40,1.85]$ & & & & \\
\hline Gennaro ISMENO 2000 & & & 0.24 & 1.36 & $1.6 \%$ & $1.27[0.09,18.28]$ & & & & \\
\hline Huynh-Quang Tri Ho 2 & & & 0.43 & 0.6 & $6.0 \%$ & $1.54[0.47,4.98]$ & & & & \\
\hline M. J. Antunes 1990 & & & -1.38 & 0.22 & $14.0 \%$ & $0.25[0.16,0.39]$ & & $\varpi$ & & \\
\hline Paneer Selvam Krishna & Moorthy 2018 & & -1.85 & 0.48 & $7.9 \%$ & $0.16[0.06,0.40]$ & & 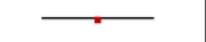 & & \\
\hline Sachin Talwar 2007 & & & -0.53 & 0.33 & $11.1 \%$ & $0.59[0.31,1.12]$ & & & & \\
\hline Terrence M. Yau 1999 & & & -0.96 & 0.2 & $14.5 \%$ & $0.38[0.26,0.57]$ & & $\varpi$ & & \\
\hline Wan Kee Kim 2018 & & & -0.31 & 0.38 & $9.9 \%$ & $0.73[0.35,1.54]$ & & & 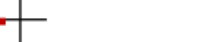 & \\
\hline Yao-Chang WANG 200 & & & 0.06 & 0.78 & $4.1 \%$ & $1.06[0.23,4.90]$ & & & & \\
\hline Yuqing Jiao 2019 & & & -1.07 & 0.45 & $8.5 \%$ & $0.34[0.14,0.83]$ & & . & & \\
\hline Total $(95 \% \mathrm{Cl})$ & & & & & $100.0 \%$ & $0.49[0.34,0.70]$ & & & & \\
\hline $\begin{array}{l}\text { Heterogeneity: } \mathrm{Tau}^{2}= \\
\text { Test for overall effect: }\end{array}$ & $\begin{array}{l}19 ; \mathrm{Chi}^{2}=24.77, \mathrm{df} \\
=3.95(\mathrm{P}<0.0001)\end{array}$ & $f=11$ & $(P=0.01$ & 10); $1^{2}=$ & $=56 \%$ & & 0.01 & $\begin{array}{l}0.1 \\
\text { Favours [MVP] }\end{array}$ & ] 1 Favours [MVR] & 100 \\
\hline $\begin{array}{l}\text { B } \\
\text { Study or Subgroup }\end{array}$ & $\log [$ & [Hazar & d Ratio] & SE & Weight & $\begin{array}{l}\text { Hazard Ratio } \\
\text { IV, Fixed, 95\% CI }\end{array}$ & & $\begin{array}{r}\text { Hazard } \\
\text { IV, Fixed, }\end{array}$ & $\begin{array}{l}\text { d Ratio } \\
\text {, } 95 \% \mathrm{Cl}\end{array}$ & \\
\hline Bo Remenyi 2013 & & & -0.94 & 0.64 & $3.2 \%$ & $0.39[0.11,1.37]$ & & & $F$ & \\
\hline Gennaro ISMENO 2000 & & & 0.24 & 1.36 & $0.7 \%$ & $1.27[0.09,18.28]$ & & & & \\
\hline Joon Bum Kim 2010 & & & -0.69 & 0.48 & $5.8 \%$ & $0.50[0.20,1.29]$ & & - & - & \\
\hline M. J. Antunes 1990 & & & -0.67 & 0.24 & $23.0 \%$ & $0.51[0.32,0.82]$ & & $\varpi$ & & \\
\hline Paneer Selvam Krishna & Moorthy 2018 & & -1.09 & 0.61 & $3.6 \%$ & $0.34[0.10,1.11]$ & & & & \\
\hline Sachin Talwar 2007 & & & -0.53 & 0.33 & $12.2 \%$ & $0.59[0.31,1.12]$ & & & & \\
\hline Terrence M. Yau 1999 & & & -0.85 & 0.3 & $14.7 \%$ & $0.43[0.24,0.77]$ & & $\longrightarrow$ & & \\
\hline Wan Kee Kim 2018 & & & -0.62 & 0.19 & $36.8 \%$ & $0.54[0.37,0.78]$ & & $\rightarrow-$ & & \\
\hline Total $(95 \% \mathrm{Cl})$ & & & & & $100.0 \%$ & $0.51[0.40,0.64]$ & & & & \\
\hline $\begin{array}{l}\text { Heterogeneity: } \mathrm{Chi}^{2}=1 \\
\text { Test for overall effect: }\end{array}$ & $\begin{array}{l}.70, d f=7(P=0.97) \\
=5.90(P<0.00001\end{array}$ & ;) $1^{2}=c$ & & & & & 0.01 & $\begin{array}{c}1 \\
0.1\end{array}$ & 1 Favours [MVP] & 100 \\
\hline$C_{\text {Study or Subgroup }}$ & log[Hazard Ratio] & SE & Weight & $\begin{array}{r}\mathrm{Hazi} \\
\mathrm{IV}, \mathrm{Fi})\end{array}$ & $\begin{array}{l}\text { ard Ratio } \\
\text { xed, } 95 \% \text { C }\end{array}$ & & $\begin{array}{l}\text { Hazarc } \\
\text { IV, Fixed }\end{array}$ & $\begin{array}{l}\text { d Ratio } \\
\text {, } 95 \% \mathrm{Cl}\end{array}$ & & \\
\hline M. J. Antunes 1990 & -0.98 & 0.24 & $31.7 \%$ & 0.38 & {$[0.23,0.60$} & & $\rightarrow-$ & & & \\
\hline Terrence M. Yau 1999 & -1.01 & 0.26 & $27.0 \%$ & 0.36 & {$[0.22,0.61$} & & & & & \\
\hline Wan Kee Kim 2018 & -1.42 & 0.21 & $41.4 \%$ & 0.24 & {$[0.16,0.36$} & & & & & \\
\hline Total $(95 \% \mathrm{Cl})$ & & & $100.0 \%$ & 0.31 & {$[0.24,0.40$} & & & & & \\
\hline $\begin{array}{l}\text { Heterogeneity: } \mathrm{Chi}^{2}= \\
\text { Test for overall effect: }\end{array}$ & $\begin{array}{l}42, d f=2(P=0.30) \\
=8.66(P<0.00001\end{array}$ & ;) $1^{2}=$ & & & & $\begin{array}{c}1 \\
0.1 \\
\text { Favou }\end{array}$ & [MVP] & $\begin{array}{cc}10 \\
\text { Favours [MVR] }\end{array}$ & $\overrightarrow{100}$ & \\
\hline
\end{tabular}

Figure 3 Meta-analysis for long-term survival. (A) MVP vs. MVR; (B) MVP vs. MVR (mech-valves); (C) MVP vs. MVR (bio-valves). MVP, mitral valve repair; MVR, mitral valve replacement.

six $(8,15,19,23-25)$ of which documented details related to mechanical valves, and 3 of which $(8,19,25)$ provided details related to bioprosthetic valves. While the summary HR suggested that the reoperation rate following MVR or MVR (mech-valves) was lower than that after MVP, no significant differences were observed between MVR (biovalves) and MVP. The heterogeneity among studies in the MVR (bio-valves) group was high $\left(\mathrm{I}^{2}=56 \%, \mathrm{P}=0.01\right)$. A random effects model was applied, and the exclusion of each study in sequence did not influence the overall results. MVP vs. MVR: HR: 1.96, 95\% CI: 1.48-2.60, Figure 4A; MVP vs. MVR (mech-valves): HR: 2.4, 95\% CI: 1.72-3.36, Figure 4B; MVP vs. MVR (bio-valves): HR: 0.8, 95\% CI:
$0.37-1.73, \mathrm{P}=0.57$, Figure $4 C$.

\section{Freedom from valve-related events}

All valve-related events are reported in accordance with the revised guidelines published by the Ad Hoc Liaison Committee for Standardizing Definitions for Prosthetic Heart Valve Morbidity [2008] (20,21). Of the 16 included studies, $4(1,8,19,23)$ provided information to allow the determination of freedom from valve-related events, although significant heterogeneity was evident $\left(\mathrm{I}^{2}=74 \%, \mathrm{P}=0.009\right)$; however, this heterogeneity was considerably reduced after the removal of the study by Krishna Moorthy et al. (19), 


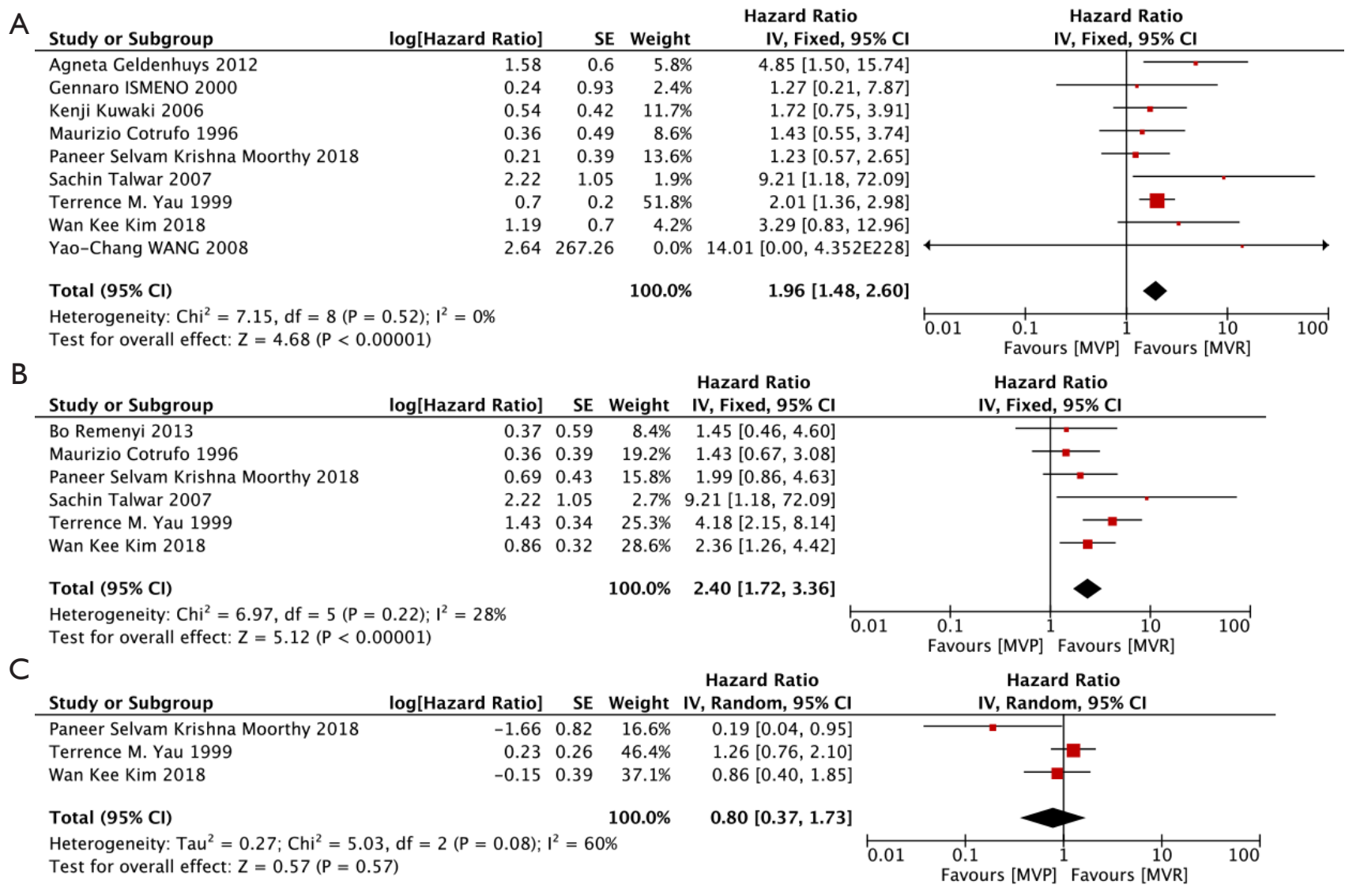

Figure 4 Meta-analysis for freedom from reoperation. (A) MVP vs. MVR; (B) MVP vs. MVR (mech-valves); (C) MVP vs. MVR (bio-valves). MVP, mitral valve repair; MVR, mitral valve replacement.

which did not influence the overall results. Three $(8,19,23)$ of the four studies provided details related to mechanical and bioprosthetic valves. The analyses demonstrated a lower rate of valve-related events in the MVP group compared with the MVR group, irrespective of whether mechanical or bioprosthetic valves were used (MVP vs. MVR: HR: 0.62, 95\% CI: 0.40-0.95, Figure 5A; MVP vs. MVR (mech-valves): HR: 0.55 , 95\% CI: $0.40-0.75$, Figure 5B; MVP vs. MVR (bio-valves): HR: 0.42, 95\% CI: 0.28-0.63, Figure 5C).

\section{Freedom from major adverse events}

Major adverse events were defined as thrombosis, embolism, and hemorrhage. Five studies $(14,15,19,23,24)$ provided sufficient data to facilitate the extraction of HR and their standard errors; however, the heterogeneity was significant $\left(\mathrm{I}^{2}=85 \%, \mathrm{P}<0.0001\right)$, and so OR was used instead of HR, with sufficient data obtained from ten studies $(1,8,14-16,18,20-22,24)$. The results demonstrated that major adverse events were less common in the MVP group (MVP vs. MVR: OR: 0.42, 95\% CI: 0.32-0.55, Figure 6).

\section{Analysis of patients with AVR}

Information on patients undergoing concomitant AVR was obtained from three studies $(18,21,24)$. No significant differences between the MVP and MVR group in early mortality and long-term survival were observed. The rate of mitral reoperation was shown to be higher in the MVP group (early mortality: MVP vs. MVR: OR: $0.92,95 \%$ CI: 0.43-1.98, $\mathrm{P}=0.83$, Figure 7A; long-term survival: MVP vs. MVR: HR: $0.76,95 \%$ CI: 0.46-1.72, P=0.26, Figure $7 B$; freedom from mitral reoperation: MVP vs. MVR: HR: 2.11, 95\% CI: 1.05-4.24, Figure 7C).

\section{Discussion}

MVP and MVR are two independent therapeutic 


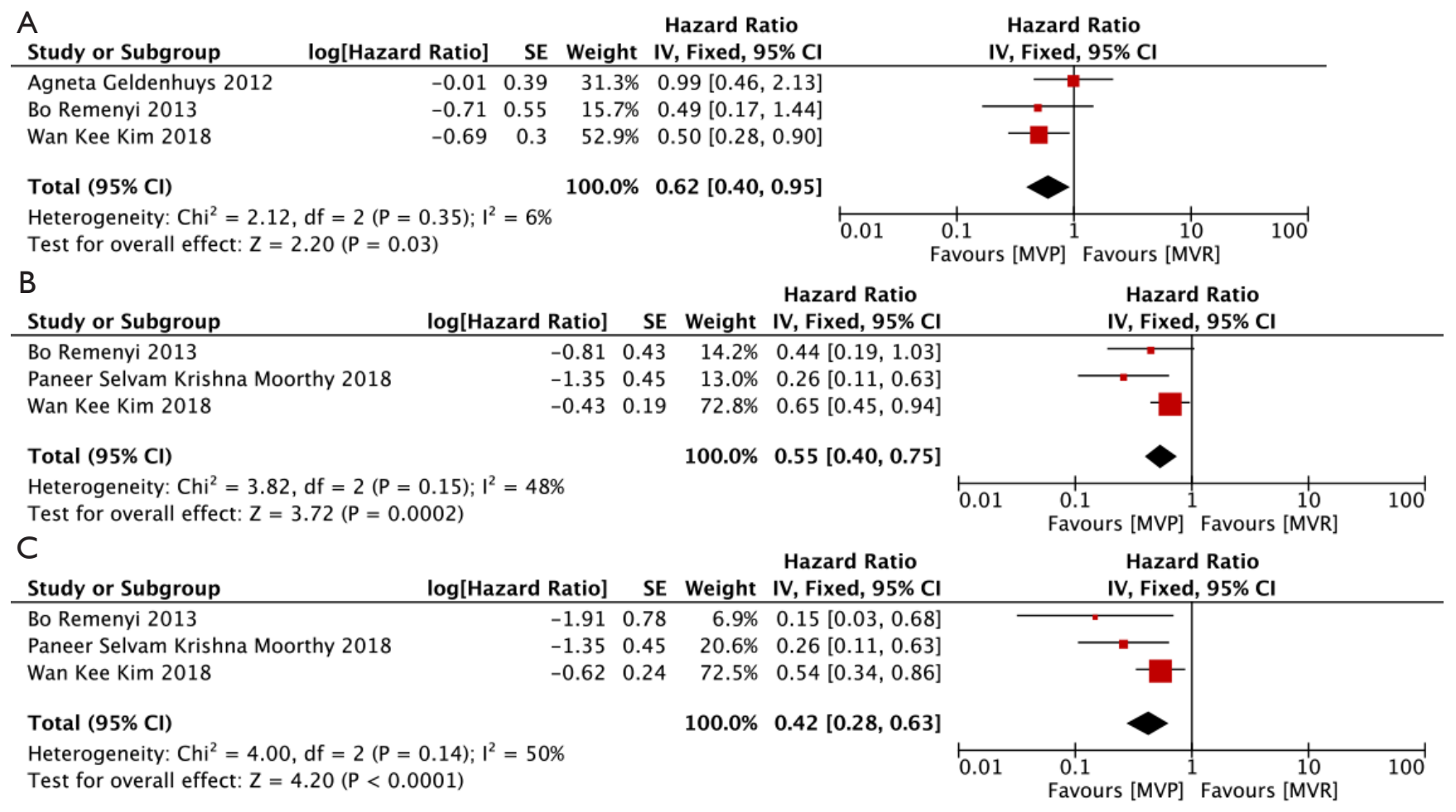

Figure 5 Meta-analysis for freedom from valve-related events. (A) MVP vs. MVR; (B) MVP vs. MVR (mech-valves); (C) MVP vs. MVR (bio-valves). MVP, mitral valve repair; MVR, mitral valve replacement.

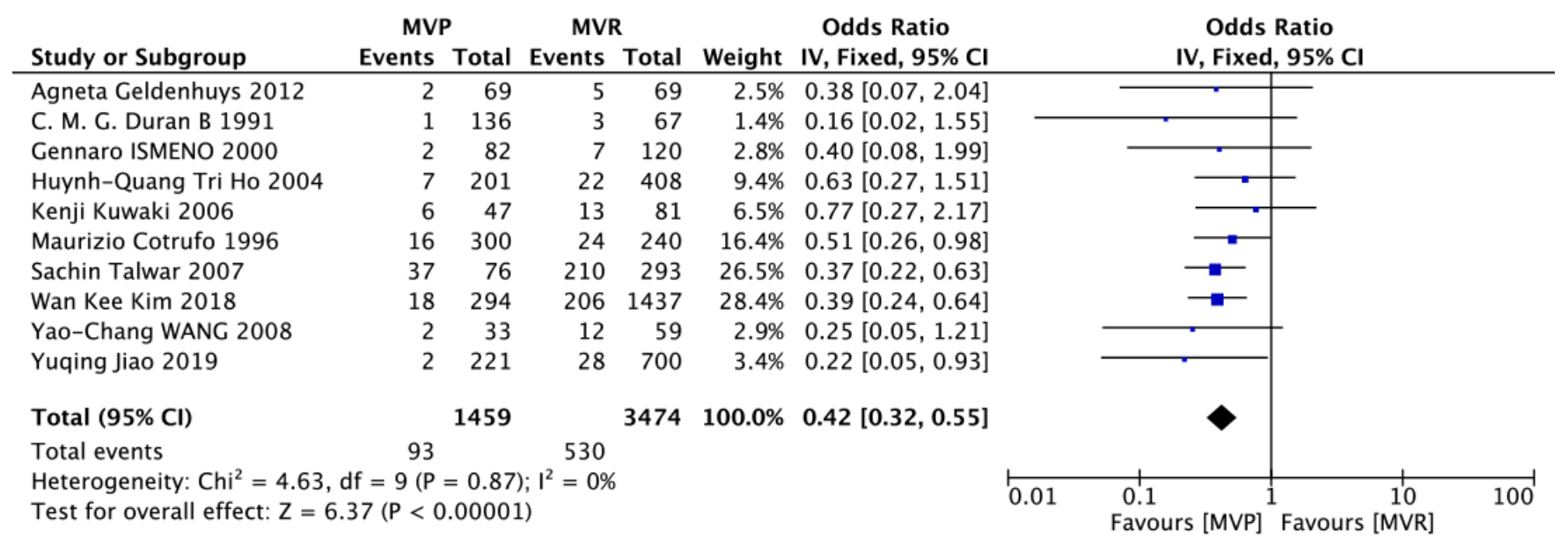

Figure 6 Meta-analysis for freedom from major adverse events between MVP and MVR. MVP, mitral valve repair; MVR, mitral valve replacement.

techniques for treating mitral valve disease. MVP has been the preferred choice for degenerative, myxomatous, or ischemic mitral valve legions, as it has the advantages of low operative mortality, low early morbidity, excellent longterm survival, and freedom from reoperation (4,5,27-29).
However, for patients with RHD, MVP's superiority remains controversial (30). The repair of the rheumatic mitral valves is technically more difficult, challenging, and complex due to its pathological features, which include commissural fusion, shortening and fusion of chordae, and 


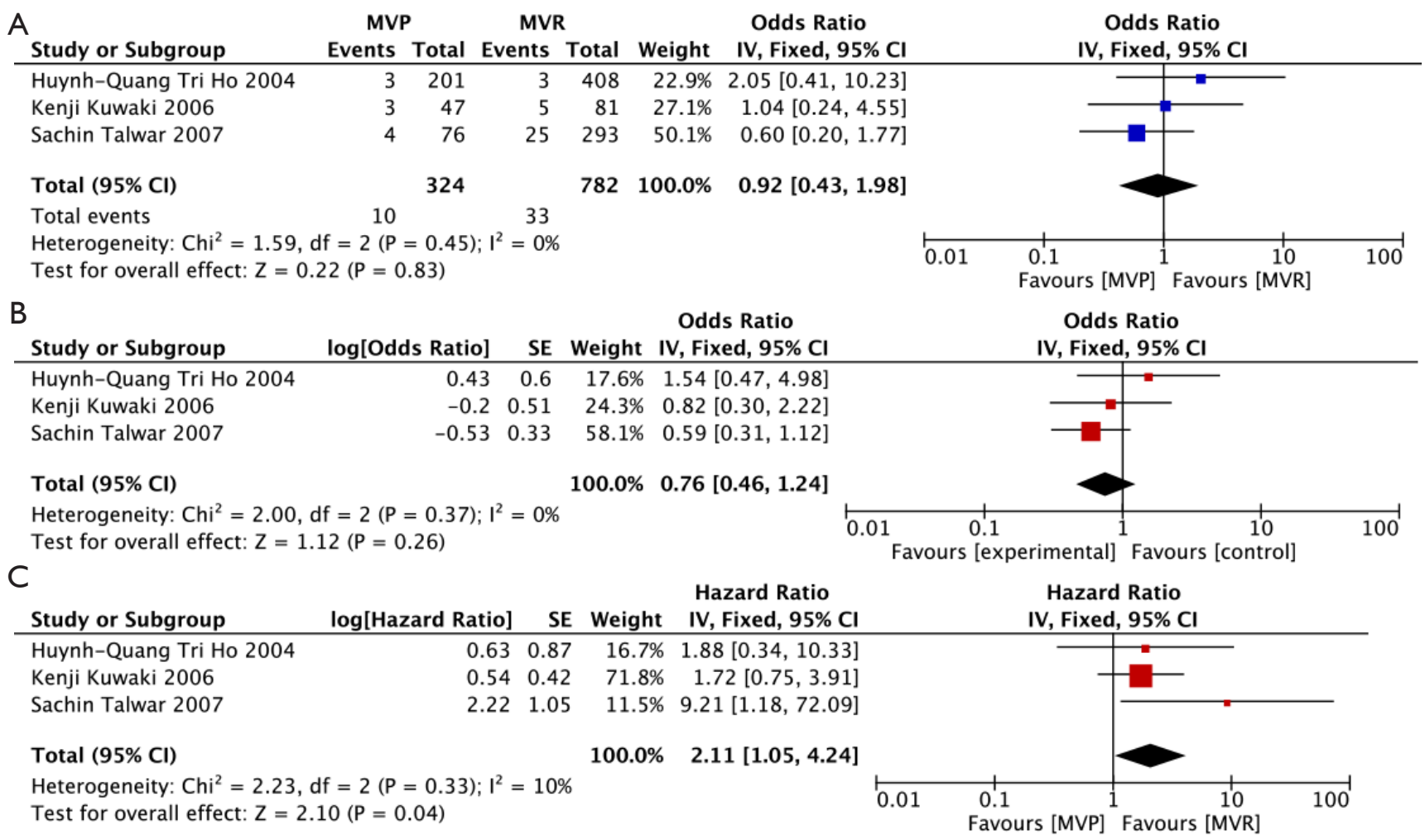

Figure 7 Comparison between MVP and MVR in patients with AVR. (A) Early mortality; (B) long-term survival; (C) freedom from reoperation. MVP, mitral valve repair; MVR, mitral valve replacement.

leaflet thickening (5). Rheumatic mitral valvular sub-valvular pathology and rheumatic pathology progression (6-8) also contribute to concerns over the poor durability of MVP in rheumatic mitral disease. The aim of this meta-analysis was thus to evaluate the available literature that compared the clinical outcomes of MVP and MVR in patients with RHD.

Rheumatic pathology influences the whole mitral valve structure, including the leaflets, annuls, chordae, and papillary muscles. Different reconstructive techniques are used according to the form, structure, and functionality of mitral valves and surgeons' experience. As displayed in Table 1, classical mitral valve reconstruction techniques contain commissurotomy, decalcification, ring, chordae replacement or formation, and leaflet formation. In recent years, several improvements in repair techniques have resulted in superior outcomes. The replacement of chordal shortening or transferring with artificial chordae made of polytetrafluoroethylene can prevent continuous elongation or chordal rupture (31). Leaflet extension is an established technology and can increase leaflet area and mobility. It is limited by the shrinkage and thickening of the pericardium, but this process can be delayed by the application of glutaraldehyde (32). Annuloplasty primarily involves applying a rigid or semirigid prosthetic ring or band (33) to correct annular dilatation and deformity (19). Repair techniques have been evolving dramatically, and novel techniques, including RHD, have yielded better outcomes and have extended the scope of valve repair; however, the long-term durability of the repair procedure in RHD patients is not known.

Clinical outcomes of MVP for RHD varied widely across different institutions, with diverse and conflicting conclusions drawn in mortality, complications, and reoperation in many studies $(1,13-15,25)$ when compared with MVR (1,13-15,25). In light of the variable anticoagulant periods, anticoagulant intensities, pathological changes, etc., that occur after implantation of mechanical and bioprosthetic valves, treating them a single entity for comparison with valvuloplasty may create confusion in some analyses (19). In this study, for the first time, we separated mechanical valves from bioprosthetic valves, and compared the clinical outcomes of MVP with mechanical valves and bioprosthetic vales separately.

Analysis of the combined the data for mechanical and 
bioprosthetic valves compared to MVP indicated that early mortality, late mortality, ratio of valve-related events, and major adverse events were lower in the MVP group, with more patients requiring reoperation. It thus appears that the suitability of MVP in RHD remains controversial. However, when the data from mechanical valves were segregated from those of bioprosthetic valves prior to comparison with MVP, lower early and late mortality and fewer valve-related and major adverse events were consistently found in the MVP group, irrespective of valve-type. No difference in the rate of reoperation was noted between MVP and MVR (biovalves), while patients in the MVP group showed a higher risk of requiring reoperations (mech-valves).

This can be easily explained by the fact that, most of patients died of cardiac insufficiency and MVP can preserve the subvalvular apparatus and protect the left ventricular function; thus, MVP can reduce the incidence of death due to left ventricular dysfunction (34-36). Secondly, MVP is associated with superior hemodynamics across the mitral valves, similar to normal physiology $(14,20)$, and can contribute to left ventricular function recovery. Thirdly, the preservation of autogenous valves reduces the possibility of perivalvular leakage and the rate of valve-related events. Finally, the lack of a requirement for long-term anticoagulant use facilitates the prevention of thromboembolism and hemorrhage $(14,22,24)$. However, the processing rheumatic activity and sub-valvular pathology in RHD leads to possible progression of rheumatic pathological changes after MVP and contributes to its higher reoperation rate (6-8) compared with MVR (mechvalves). However, once bioprosthetic valves are implanted, decay commences with dystrophic calcification, thrombosis, and fibrous tissue overgrowth (37), which was similar to the pathology in RHD. This may explain the lack of difference in reoperation rates between MVP and bioprosthetic valve replacement.

The patients in the MVP group were younger, which might have contributed to lower mortality, fewer complications, and more reoperations since youth is associated with superior body function and improved recovery from the surgery. As Yau indicates, a more aggressive repair occurs in younger patients (25), and the rate of repair is age-dependent but inversely related to age (6). Different ages represent different stages of the disease (38). The incidence of inflammation or scarring increases with age, making MVP more difficult resulting in a less favorable postoperative outcome (14). However, the histological process has shown to stabilize in patients aged over 50 years (38) which potentially leads to a greater propensity for better outcomes in this age group. It should be noted that while age may play a role in postoperative outcomes, it is not a determinant.

We further found that fewer patients MVP group exhibited atrial fibrillation but underwent a greater number of maze procedures, which may theoretically be beneficial in achieving better postoperative heart function, normal hemodynamics, and lower incidence of thromboembolism. However, neither atrial fibrillation nor age are predictors of improved survival (25), and further studies are required to explore the roles of these predictive factors.

Although MVP can reduce early and late mortality, along with the ratio of valve-related events and major adverse events when compared with mechanical valves, MVP patients may be at a higher risk of reoperation. In addition, the operative mortality for those undergoing repeat heart valve replacements is $7-12 \%$, and higher when the indication is endocarditis or a thrombosed valve (39). Durability in terms of freedom from subsequent reoperation is an important consideration for valve repair procedures. The actual rate of reoperation differed across each study, and the HR varied from 1.23 to 14.1. Fu et al. reported that MVP in patients with RHD may arise from numerous factors: age, mitral morphology, the time of surgery, presence of moderate pulmonary hypertension, and usage of penicillin prophylactic treatment (35). Two requirements must be met for achieving successful repair: years of experience in performing this repair, and familiarity with the valve's morphology (3). The clinical decision to repair or replace the valve is always based on the physicians' judgment and experience (36). Valve repair requires robust knowledge of valvular anatomy and the multitude of existing techniques. A thorough understanding of three-dimensional mitral valve anatomy and the cardiac cycle functions related to those mechanisms that contribute to the valve dysfunction is critical to the success of MVP (40). The specific valvular morphology has also been reported as a risk factor for later mitral valve failure after MVP in rheumatic disease $(4,21)$, with the existence of a pliable anterior leaflet being critically important. Although reconstruction is technically possible when the anterior leaflet is thickened, the repaired valve will most likely become stenotic in the long term. Moreover, an adequate zone of coaptation between the anterior and posterior leaflets is also crucial (41). Therefore, patients having the appropriate surgical indications is essential for achieving positive long-term results in MVP. In summary, if a given institution has an 
acceptable reoperation rate after initial surgery, MVP can be performed for suitable patients by skilled surgeons.

For elderly patients or patients with contraindications of anti-coagulation, bioprosthetic valves have been recommended over their mechanical counterparts (42). Since the reoperation rate of MVP is not higher than that of bioprosthetic valve replacement and has the advantages of lower mortality and fewer complications, MVP is more suitable for these patients.

Concomitant aortic valve replacement is performed in $20 \%$ to $50 \%$ of patients with rheumatic MV diseases (4). Analysis of combined valve diseases that did not distinguish RHD from non-RHD revealed that MVP was associated with improved early and late mortality and similar MV reoperation rates among patients with AVR $(4,43,44)$. Whether similar results occur in RHD remains unclear and requires further discussion. Many groups have limited experience with combined AVR and MVP (24), and related studies are few in number. According to our search strategy, studies related to mitral valve surgery in patients undergoing concomitant aortic valve surgery were already all included.

For patients combined with AVR, no difference in early mortality and long-term survival was observed between the MVP and MVR group, but the rate of mitral reoperation was higher in the MVP group. However, $97.4 \%$ of patients involved chose mechanical valves. This is similar to the comparison between valve repair and mechanical valve replacement. It is easy to understand why reoperation occurred at a higher frequency in the MVP group. Considering the lack of difference in mortality, the progression of the rheumatic pathology and more skills and longer cardiopulmonary bypass are needed for MVP. MVR might be the first choice for patients with double rheumatic valve disease, if aortic valve replacement is needed. More studies are needed for future exploration of this issue.

\section{Limitations}

Several limitations of this meta-analysis should be noted. Firstly, due to the lack of randomized controlled studies, only retrospective studies were involved. Secondly, the number of studies in some analyses was low, which might have increased the risk of selection bias. Thirdly, the operative years reported in the studies had a broader range which could have reduced the comparability of the studies in the analysis. Fourthly, the methods and techniques of mitral repair varied across the studies, partly due to the relative experience of the surgeons involved.

\section{Conclusions}

In conclusion, for patients with RHD, both MVP and MVR are beneficial, and have their respective strengths and weaknesses. It is thus still difficult to conclude which is the superior approach. For skilled surgeons, MVP can be performed for suitable patients when feasible; MVR may be a better choice over MVP if aortic valves need to be replaced concomitantly. More randomized controlled trials that separately analyze mechanical valves and biological valves should be conducted.

\section{Acknowledgments}

Funding: This work was supported by grants from the Natural Science Foundation of Hubei Province (No. 2017CFB647); and the National Natural Science Foundation of China (No. 81700339).

\section{Footnote}

Reporting Checklist: The authors have completed the PRISMA reporting checklist. Available at http://dx.doi. org/10.21037/atm-20-3542

Conflicts of Interest: All authors have completed the ICMJE uniform disclosure form (available at http://dx.doi. org/10.21037/atm-20-3542), and report grants from National Natural Science Foundation of China (81700339), grants from Natural Science Foundation of Hubei Province (2017CFB647), during the conduct of the study. The other authors have no conflicts of interest to declare.

Etbical Statement: The authors are accountable for all aspects of the work in ensuring that questions related to the accuracy or integrity of any part of the work are appropriately investigated and resolved.

Open Access Statement: This is an Open Access article distributed in accordance with the Creative Commons Attribution-NonCommercial-NoDerivs 4.0 International License (CC BY-NC-ND 4.0), which permits the noncommercial replication and distribution of the article with the strict proviso that no changes or edits are made and the original work is properly cited (including links to both the formal publication through the relevant DOI and the license). 
See: https://creativecommons.org/licenses/by-nc-nd/4.0/.

\section{References}

1. Geldenhuys A, Koshy JJ, Human PA, et al. Rheumatic Mitral Repair Versus Replacement in a Threshold Country: The Impact of Commissural Fusion. J Heart Valve Dis 2012;21:424-32.

2. Sarris GE, Cahill PD, Hansen DE, et al. Restoration of left ventricular systolic performance after reattachment of the mitral chordae tendineae. The importance of valvular-ventricular interaction. J Thorac Cardiovasc Surg 1988;95:969-79.

3. Shuhaiber J, Anderson RJ. Meta-analysis of clinical outcomes following surgical mitral valve repair or replacement. Eur J Cardiothorac Surg 2007;31:267-75.

4. Saurav A, Alla VM, Kaushik M, et al. Outcomes of mitral valve repair compared with replacement in patients undergoing concomitant aortic valve surgery: a metaanalysis of observational studies. Eur J Cardiothorac Surg 2015;48:347-53.

5. Kim YH, Czer LS, Soukiasian HJ, et al. Ischemic mitral regurgitation: revascularization alone versus revascularization and mitral valve repair. Ann Thorac Surg 2005;79:1895-901.

6. Duran CM, Gometza B, Saad E. Valve repair in rheumatic mitral disease: an unsolved problem. J Card Surg 1994;9:282-5.

7. Skoularigis J, Sinovich V, Joubert G, et al. Evaluation of the long-term results of mitral valve repair in 254 young patients with rheumatic mitral regurgitation. Circulation 1994;90:II167-74.

8. Kim WK, Kim HJ, Kim JB, et al. Clinical outcomes in 1731 patients undergoing mitral valve surgery for rheumatic valve disease. Heart 2018;104:841-8.

9. Wells GA, Shea B, O'Connell D, et al. The NewcastleOttawa Scale (NOS) for assessing the quality of non-randomised studies in meta-analyses. Available online: http://www.ohri. ca/programs/clinical_epidemiology/oxford.asp. 2014.

10. Parmar MK, Torri V, Stewart L. Extracting summary statistics to perform meta-analyses of the published literature for survival endpoints. Stat Med 1998;17:2815-34.

11. Williamson PR, Smith CT, Hutton JL, et al. Aggregate data meta-analysis with time-to-event outcomes. Stat Med 2002;21:3337-51.

12. Tierney JF, Stewart LA, Ghersi D, et al. Practical methods for incorporating summary time-to-event data into meta- analysis. Trials 2007;8:16.

13. Kim JB, Kim HJ, Moon DH, et al. Long-term outcomes after surgery for rheumatic mitral valve disease: valve repair versus mechanical valve replacement. Eur J Cardiothorac Surg 2010;37:1039-46.

14. Wang YC, Tsai FC, Chu JJ, et al. Midterm Outcomes of Rheumatic Mitral Repair Versus Replacement. Int Heart J 2008;49:565-76.

15. Cotrufo M, Renzulli A, Vitale N, et al. Long-term follow-up of open commissurotomy versus bileaflet valve replacement for rheumatic mitral stenosis. Eur J Cardiothorac Surg 1997;12:335-9.

16. Duran CM, Gometza B, Balasundaram S, et al. A feasibility study of valve repair in rheumatic mitral regurgitation. Eur Heart J 1991;12 Suppl B:34-8.

17. Russell EA, Walsh WF, Reid CM, et al. Outcomes after mitral valve surgery for rheumatic heart disease. Heart Asia 2017;9:e010916.

18. Ho HQ, Nguyen VP, Phan KP, et al. Mitral valve repair with aortic valve replacement in rheumatic heart disease. Asian Cardiovasc Thorac Ann 2004;12:341-5.

19. Krishna Moorthy PS, Sivalingam S, Dillon J, et al. Is it worth repairing rheumatic mitral valve disease in children? Long-term outcomes of an aggressive approach to rheumatic mitral valve repair compared to replacement in young patients. Interact Cardiovasc Thorac Surg 2019;28:191-8.

20. Jiao Y, Luo TG, Zhang HB, et al. Repair versus replacement of mitral valves in cases of severe rheumatic mitral stenosis: mid-term clinical outcomes. J Thorac Dis 2019;11:3951-61.

21. Kuwaki K, Kawaharada N, Morishita K, et al. Mitral valve repair versus replacement in simultaneous mitral and aortic valve surgery for rheumatic disease. Ann Thorac Surg 2007;83:558-63.

22. Ismeno G, Renzulli A, De Feo M, et al. Surgery of rheumatic mitral stenosis: comparison of different techniques. Acta Cardiol 2001;56:155-61.

23. Remenyi B, Webb R, Gentles T, et al. Improved longterm survival for rheumatic mitral valve repair compared to replacement in the young. World J Pediatr Congenit Heart Surg 2013;4:155-64.

24. Talwar S, Mathur A, Choudhary SK, et al. Aortic valve replacement with mitral valve repair compared with combined aortic and mitral valve replacement. Ann Thorac Surg 2007;84:1219-25.

25. Yau TM, El-Ghoneimi YA, Armstrong S, et al. Mitral valve repair and replacement for rheumatic disease. J 
Thorac Cardiovasc Surg 2000;119:53-60.

26. Antunes MJ. Mitral valvuloplasty, a better alternative. Comparative study between valve reconstruction and replacement for rheumatic mitral valve disease. Eur J Cardiothorac Surg 1990;4:257-62; discussion 263-54.

27. Gillinov AM, Cosgrove DM, Blackstone EH, et al. Durability of mitral valve repair for degenerative disease. J Thorac Cardiovasc Surg 1998;116:734-43.

28. David TE, Omran A, Armstrong S, et al. Long-term results of mitral valve repair for myxomatous disease with and without chordal replacement with expanded polytetrafluoroethylene sutures. J Thorac Cardiovasc Surg 1998;115:1279-85.

29. David TE, Armstrong S, Sun Z, et al. Late results of mitral valve repair for mitral regurgitation due to degenerative disease. Ann Thorac Surg 1993;56:7-12; discussion 13-14.

30. Harb SC, Griffin BP. Mitral Valve Disease: a Comprehensive Review. Curr Cardiol Rep 2017;19:73.

31. Bortolotti U, Milano AD, Frater RWM. Mitral Valve Repair With Artificial Chordae: A Review of Its History, Technical Details, Long-Term Results, and Pathology. Ann Thorac Surg 2012;93:684-91.

32. Zegdi R, Ould-Isselmou K, Fabiani JN, et al. Pericardial patch anterior leaflet extension in rheumatic mitral insufficiency. Eur J Cardiothorac Surg 2011;39:1061-3.

33. Yakub MA, Moorthy PSK, Sivalingam S, et al. Contemporary long-term outcomes of an aggressive approach to mitral valve repair in children: is it effective and durable for both congenital and acquired mitral valve lesions? Eur J Cardiothorac Surg 2016;49:553-60.

34. Lee EM, Shapiro LM, Wells FC. Importance of subvalvular preservation and early operation in mitral valve surgery. Circulation 1996;94:2117-23.

35. Fu JT, Popal MS, Zhang HB, et al. A meta-analysis of late

Cite this article as: Jiang Y, Wang C, Li G, Chen S. Clinical outcomes following surgical mitral valve repair or replacement in patients with rheumatic heart disease: a meta-analysis. Ann Transl Med 2021;9(3):204. doi: 10.21037/atm-20-3542 outcomes of mitral valve repair in patients with rheumatic heart disease. J Thorac Dis 2017;9:4366-75.

36. Wang Z, Zhou C, Gu H, et al. Mitral valve repair versus replacement in patients with rheumatic heart disease. J Heart Valve Dis 2013;22:333-9.

37. Valente M, Minarini M, Thiene G, et al. The pathology of Hancock standard porcine valve prosthesis: a 20-year span of experience. J Card Surg 1990;5:328-35.

38. Antunes MJ. Repair of rheumatic mitral valve regurgitation: how far can we go? Eur J Cardiothorac Surg 2013;44:689-91.

39. Jones JM, O'Kane H, Gladstone DJ, et al. Repeat heart valve surgery: risk factors for operative mortality. J Thorac Cardiovasc Surg 2001;122:913-8.

40. Pomerantzeff PM, Brandao CM, Leite Filho OA, et al. Mitral valve repair in rheumatic patients with mitral insuficiency: twenty years of techniques and results. Rev Bras Cir Cardiovasc 2009;24:485-9.

41. Pomerantzeff PMA. Mitral Valve Repair in Young Rheumatic Patients. Arq Bras Cardiol 2019;113:757.

42. Nishimura RA, Otto CM, Bonow RO, et al. 2017 AHA/ ACC Focused Update of the 2014 AHA/ACC Guideline for the Management of Patients With Valvular Heart Disease: A Report of the American College of Cardiology/ American Heart Association Task Force on Clinical Practice Guidelines. Circulation 2017;135:e1159-95.

43. Gillinov AM, Blackstone EH, White J, et al. Durability of combined aortic and mitral valve repair. Ann Thorac Surg 2001;72:20-7.

44. Gillinov AM, Blackstone EH, Cosgrove DM, et al. Mitral valve repair with aortic valve replacement is superior to double valve replacement. J Thorac Cardiov Surg 2003;125:1372-87. 